\title{
Optimum performance of the small-scale open and direct solar thermal Brayton cycle at various environmental conditions and constraints (IGEC-VI-2011-044)
}

\author{
W.G. le Roux, T. Bello-Ochende* and J.P. Meyer \\ Department of Mechanical and Aeronautical Engineering, University of Pretoria, Private Bag X20, Hatfield, Pretoria \\ 0028 , South Africa \\ * Corresponding author: Tel.: +2712 4203105 ; fax: +2712 3625124. \\ E-mail address: tunde.bello-ochende@up.ac.za.
}

\begin{abstract}
The Brayton cycle's heat source can be obtained from solar energy instead of the combustion of fuel. The irreversibilities of the open and direct solar thermal Brayton cycle with recuperator are mainly due to heat transfer across a finite temperature difference and fluid friction, which limit the net power output of such a system. In this work, the method of total entropy generation minimisation is applied to optimise the geometries of the receiver and recuperator at various steady-state weather conditions. For each steady-state weather condition, the optimum turbine operating point is also found. The authors specifically investigate the effect of wind and solar irradiance on the maximum net power output of the system. The effects of other conditions and constraints, on the maximum net power output, are also investigated. These include concentrator error, concentrator reflectivity and maximum allowable surface temperature of the receiver. Results show how changed solar beam irradiance and wind speed affect the system net power output and optimum operating point of the micro-turbine. A dish concentrator with fixed focal length, an off-the-shelf micro-turbine and a modified cavity receiver is considered.
\end{abstract}

Keywords: optimum, solar, Brayton, receiver, recuperator, geometry

\section{Introduction}

The solar thermal Brayton cycle uses the concentrated power of the sun as a heat source to generate mechanical power. Low operation and maintenance costs make the small-scale open and direct solar thermal Brayton cycle with recuperator attractive for power generation. The recuperator can increase the efficiency of the Brayton cycle and it allows the compressor to operate at lower pressure ratios. The Brayton cycle is definitely worth studying when comparing its efficiency [1] and cost [2] with those of other power cycles. A black solar receiver, mounted at the focus of a parabolic dish concentrator can be sized such that it absorbs the maximum amount of heat [3]. Sendhil Kumar and Reddy [4] compared different types of cavity receivers numerically and suggested that the modified cavity receiver may be preferred in a solar dish collector system. The total heat loss rate from the modified cavity receiver due to convection, radiation and conduction, is a function of the receiver geometry [5]. A numerical investigation of natural convection heat loss [6], an inclusion of the contribution of radiation losses [7] and an improved model for natural convection heat loss [8] was presented for the modified cavity receiver.

The irreversibilities of a small-scale solar thermal Brayton cycle with recuperator limit the net power output of such a system. These irreversibilities are mainly due to heat transfer across a finite temperature difference and fluid friction. To obtain the maximum net power output of a solar thermal Brayton cycle, a combined effort of heat transfer, fluid mechanics and thermodynamic thought is necessary. The method of total entropy generation minimisation combines these thoughts [9].

Optimisation using the second law of thermodynamics is commonly found in recent work. A second law analysis to study the effect of operating parameters on the optimum pressure ratio and component irreversibilities of the supercritical $\mathrm{CO}_{2}$ recompression Brayton cycle [10], as well as an optimisation [11] have been performed. The optimal performance parameters for the maximum exergy delivery during the collection of solar energy in a flat-plate solar air heater were established by optimising the geometries of the plate [12]. Exergy analysis has also been applied in various power studies [13].

Various authors have emphasised the importance of the optimisation of the global performance of a system, by minimising the total irreversibility rate from all the different components or processes of such a system by sizing the components accordingly [14-19]. In recent work, a geometry optimisation method based on total entropy generation minimisation was developed and was applied to establish the maximum net power output of a smallscale open and direct solar thermal Brayton cycle with cavity receiver and recuperator at any steady-state condition and various micro-turbine operating points [20]. This was done for various concentrator diameters and micro-turbines. This method allows for the global performance of the system to be optimised, by minimising the total irreversibility rate by sizing the receiver and recuperator accordingly. This optimisation was done for multiple steady-state systems with no wind and a constant solar irradiance of $1000 \mathrm{~W} / \mathrm{m}^{2}$. 
The effects of wind, receiver inclination, rim angle, atmospheric temperature and pressure, recuperator height, solar irradiance and concentration ratio on the optimum geometries and performance of the open and direct solar thermal Brayton cycle were also investigated [21]. For a specific weather condition, the geometries, operating conditions and irreversibilities of the optimised system were shown as a function of system mass flow rate. It was shown that for each specific environment and set of parameters an optimum receiver and recuperator geometry and system mass flow rate exist so that the system produces maximum net power output.

In this paper, the authors further investigate the effects that changed wind and solar irradiance have on the optimum turbine operating point of the micro-turbine. Other effects are also investigated, such as specular reflectivity and concentrator error.

\section{Model}

A micro-turbine from the Garrett range [22] and $D_{\text {conc }}=5.2 \mathrm{~m}$ is used in the analysis. The open and direct solar thermal Brayton cycle with recuperator is shown in Fig. 1. A parabolic dish supplies the solar heat for the cavity receiver.

\subsection{The control volume}

The rate of intercepted heat by the cavity receiver, $\dot{Q}^{*}$, is a function of the cavity receiver geometry. For the analysis in this work, the apparent sun's temperature as an exergy source, $T^{*}$, is assumed to be $2470 \mathrm{~K}$ [9] and at a point between the concentrator and receiver. $\dot{Q} *$ can be regarded as the intercepted power at the receiver, after the irreversibility rates due to scattering and the transformation of radiation have been deducted. $\dot{W}_{n e t}$ is the net power output of the system.

\subsection{Solar receiver model}

A section view of the modified cavity receiver suggested by Reddy and Sendhil Kumar [8] is shown in Fig. 2. The receiver inner surface is made up of a closely wound copper tube with diameter, $D_{\text {rec }}$, through which the working fluid travels. The receiver tube with length, $L_{r e c}$, constructs the half spherical cavity receiver and its aperture. Note that the tube is concentrically wound. An area ratio of $A_{w} / A_{a}=8$ is recommended [8] as it was found to be the ratio that gives the minimum heat loss rate from the cavity receiver. The diameter of the receiver can be calculated [20-21] as

$$
D_{s p h}=2 \sqrt{\left(A_{w}+A_{a}\right) / 3 \pi}
$$

Due to the area ratio constraint, the receiver diameter is a function of the receiver aperture diameter,

$$
D_{s p h}=\sqrt{3} d
$$

The receiver aperture diameter can be calculated using Eq. (3) since $A_{w}=D_{r e c} L_{r e c}$.

$$
d=\sqrt{D_{r e c} L_{r e c} / 2 \pi}
$$

For $A_{w} / A_{a}=8$, the Nusselt number, $N u_{D}=\left(h_{n c o n v} D_{s p h}\right) / k$, for natural convection heat loss rate based on receiver diameter for a 3-D receiver model can be calculated as a function of the inclination angle of the receiver [8],

$$
N u_{D}=0.698 G r_{D}^{0.209}(1+\cos \beta)^{0.968}\left(T_{w} / T_{0}\right)^{-0.317}\left(d / D_{s p h}\right)^{0.425}
$$

For $A_{w} / A_{a}=8$, the ratio of radiation heat loss to convection heat loss is a function of receiver inclination and varies between approximately 0.92 and 1.46 [7]. It is assumed that $\dot{Q}_{\text {loss, nrad }}=U \dot{Q}_{\text {loss, nconv }}$ for the modified cavity receiver, where $U$ is a function of the inclination of the receiver and varies between 1.92 and 2.46. The rate of heat loss due to natural convection and radiation is therefore

$$
\dot{Q}_{\text {loss }, \text { rad }}=0.698 G r_{D}^{0.209} U C(1+\cos \beta)^{0.968}\left(T_{w} / T_{0}\right)^{-0.317}\left(d / D_{\text {sph }}\right)^{0.425}
$$


where $C=\left(k A_{a} / D_{s p h}\right)\left(T_{w}-T_{0}\right)$.

With an assumed insulation thickness of $D / 2$, the rate of heat loss due to conduction [5] is

$\dot{Q}_{\text {loss }, \text { cond }}=\left(T_{s, \text { in }}-T_{0}\right) /\left(1 / 2 \pi D k_{\text {ins }}+1 / 2 \pi h_{\text {conv }} D^{2}\right)$

where $h_{c o n v}$ is the external heat transfer coefficient on the insulation surface.

The heat loss rate from the lower part of the receiver tube which is not insulated, due to the external forced convection of wind [5] is

$\dot{Q}_{\text {loss,conv }}=4.22 w^{0.805} \pi d^{2} / 2$

The total heat loss rate from the cavity receiver is

$$
\dot{Q}_{\text {loss }}=\dot{Q}_{\text {loss }, \text { rrad }}+\dot{Q}_{\text {loss,cond }}+\dot{Q}_{\text {loss, conv }}
$$

\subsection{Determination of net absorbed heat rate}

At the focal point of a solar concentrator, the reflected rays do not form a point but an image of finite size centred about the focal point. This is due to the sun's rays not being truly parallel and due to concentrator errors. The larger the receiver aperture diameter, the larger the rate of heat intercepted by the receiver, $\dot{Q} *$. Also, the larger the aperture diameter, the larger the heat loss rate, $\dot{Q}_{\text {loss }}$, in Eq. (8). The net rate of absorbed heat, $\dot{Q}_{n e t}$, is the intercepted heat rate minus the total heat loss rate. The sizing algorithm of Stine and Harrigan [3] is applied to determine the net absorbed heat rate, $\dot{Q}_{n e t}$, as a function of the receiver aperture diameter. The sizing algorithm considers the concentrator area, rim angle, specular reflectance, inclination, solar beam irradiance, parabolic concentrator error, wind and heat loss rate. The shadow of the receiver and its insulation is also accounted for when calculating the intercepted heat rate. The net absorbed heat rate as a function of receiver aperture diameter, from the sizing algorithm, can be numerically approximated with Eq. (9) using the discrete least squares approximation method [23], where $y_{i}$ is a set of constants used to describe the function.

$$
\dot{Q}_{n e t}=\sum_{i=0}^{10} y_{i} d^{i}
$$

In this work it is assumed that the concentrator rim angle and receiver inclination are both $45^{\circ}$. A change in concentrator rim angle and receiver inclination, do not affect the net power output of the system much [21]. Note that when the receiver aperture lies in the horizontal plane, the receiver inclination is $90^{\circ}$.

\subsection{Recuperator model}

A counterflow plate-type recuperator is used as shown in Fig. 3 . The channels with hydraulic diameter, $D_{h, r e g}$, length, $L_{r e g}$, and aspect ratio, $a / b_{\text {reg }}$ are shown. In this work the recuperator height, $H$, is chosen as $1 \mathrm{~m}$. The effect of changing the recuperator height is shown in [21]. The number of flow channels in the recuperator, $n$, depends on the recuperator height, $H$, channel height, $b$, and thickness of the channel separating surface, $t$, and can be written as a function of the channel aspect ratio,

$$
n=H /(t+b)=H /\left(t+D_{h, \text { reg }}\left((a / b)_{\text {reg }}+1\right) /\left(2(a / b)_{\text {reg }}\right)\right)
$$

Eq. (11) gives the mass flow rate per channel.

$$
\dot{m}_{c}=2 \dot{m} / n
$$

The surface area, $A_{s, r e g}$, for a channel as a function of the channel aspect ratio is

$$
A_{s, r e g}=2(a+b) L_{r e g}=D_{h, \text { reg }} L_{r e g}\left((a / b)_{r e g}+1\right)\left(1+(a / b)_{r e g}^{-1}\right)
$$


The thickness of the material between the hot and cold stream, $t$, is $1 \mathrm{~mm}$. The Reynolds number for a flow channel is

$$
\operatorname{Re}=\dot{m}_{c} D_{h, r e g}(a / b)_{r e g} / \mu a^{2}
$$

Using the definition of the hydraulic diameter and Eq. (14), the Reynolds number can be calculated with

$$
\operatorname{Re}=\frac{4(a / b)_{r e g} \dot{m}_{c}}{\mu D_{h, r e g}\left((a / b)_{r e g}+1\right)^{2}}
$$

Heat exchanger irreversibilities can be reduced by slowing down the movement of fluid through a heat exchanger [9]. Small Reynolds numbers can thus be expected for the optimised recuperator channels and the Gnielinski equation [24] can be used to determine the Nusselt number,

$$
N u_{D}=\frac{\operatorname{Pr}(\operatorname{Re}-1000)(f / 8)}{1+12.7(f / 8)^{0.5}\left(\operatorname{Pr}^{2 / 3}-1\right)}
$$

The Petukhov equation [25] is used to calculate the friction factor,

$$
f=(0.79 \ln \operatorname{Re}-1.64)^{-2}
$$

With the use of the friction factor, Reynolds number and the definition of the pressure drop [26], the pressure drop through the recuperator can be written in terms of the geometric variables as

$$
\Delta P=(0.79 \ln \operatorname{Re}-1.64)^{-2}\left(\frac{8 \dot{m}_{c}^{2}(a / b)_{r e g}^{2}}{\rho\left(a / b_{r e g}+1\right)^{4}}\right)\left(\frac{L_{r e g}}{D_{h, r e g}^{5}}\right)
$$

The recuperator efficiency $\left(\eta_{\text {reg }}\right)$ is calculated using the $\varepsilon-N T U$ method with the fouling factor for air chosen as 0.004 .

\subsection{Compressor and turbine properties}

A standard off-the-shelf micro-turbine from Honeywell [22] is considered. Note that in this work, the geometry of the micro-turbine is fixed and is not optimised. When considering geometric optimisation of components, in a system using a turbo-machine, the compressor or turbine pressure ratio can be chosen as a parameter [27-29]. In this work, the turbine operating point (turbine corrected mass flow rate and turbine pressure ratio) is chosen. The turbine corrected mass flow rate and turbine pressure ratio can be modelled with the use of the turbine map, when considering experimental results for turbines and their mass flow rates [30]. Note that the turbine corrected mass flow rate is a function of the turbine pressure ratio. A turbine isentropic efficiency of 0.8 is assumed since it is a function of the load [31] and the load is not known. The turbine operating point is thus used as parameter in the objective function so that the maximum of the objective function can be found at different parameter values.

The compressor isentropic efficiency, compressor corrected mass flow rate, compressor pressure ratio and rotational speed are intrinsically coupled to each other and are available from the compressor map [22]. The compressor isentropic efficiency is obtained with interpolation. The compressor should operate within its compressor map range, otherwise flow surge or choking can occur.

\subsection{The objective function}

The objective function is the function which is maximised by the optimisation of variables. The net power output of the system is hence written in terms of the total entropy generation rate in the system. The optimisation of the geometry variables is done over a range of turbine operating points.

\subsubsection{Temperatures and pressures in terms of geometry variables}


The temperatures and pressures of each point in Fig. 1 can be written in terms of the geometry variables. Note that $T_{1}=300 \mathrm{~K}, P_{1}=P_{10}=P_{11}=86 \mathrm{kPa}$ (see Fig. 1) and the temperatures and pressures in all the ducts are calculated with a small assumed temperature loss or pressure drop. The remaining temperatures and pressures are calculated with iteration as shown in Fig. 4. After choosing the turbine operating point, $T_{7}$ is guessed for the first iteration. For the second iteration, the system mass flow rate is guessed, where after $d P_{9-10}, P_{9}, P_{8}$ and $P_{7}$ are calculated so that the mass flow rate can be calculated using Eq. (18),

$\dot{m}_{t}=\frac{\dot{m}_{t C F} \times P_{7} / 14.7}{\sqrt{\left(T_{7}+460\right) / 519}}$

where $P_{7}$ is in psi and $T_{7}$ in degrees Fahrenheit respectively [22].

The corrected compressor mass flow rate can then be calculated with Eq. (19) since the mass flow rate through the compressor is equal to the mass flow rate through the turbine. Note that $P_{l}$ and $T_{1}$ are in psi and degrees Fahrenheit respectively [22].

$\dot{m}_{c C F}=\frac{\dot{m} \times \sqrt{\left(T_{1}+460\right) / 545}}{P_{1} / 13.95}$

For the third iteration, the compressor pressure ratio is guessed so that $d P_{3-4}, P_{6}, P_{5}, P_{4}, P_{3}$ and $P_{2}$ can be calculated. This allows for the compressor pressure ratio to be obtained with iteration.

The temperatures are found using the isentropic efficiencies and recuperator efficiency. $T_{6}$ is calculated as shown in Eq. (20) so that $T_{7}$ can be found with iteration.

$T_{6}=\left(\sum_{i=0}^{10} y_{i}{\sqrt{D_{r e c} L_{r e c} / 2 \pi}}^{i}\right) / \dot{m} c_{p 0}+T_{5}$

\subsubsection{Construction of the objective function}

For maximum net power output the total entropy generation rate is a minimum. The finite heat transfers and pressure drops in the compressor, turbine, recuperator, receiver and ducts are identified as entropy generation mechanisms. When doing an exergy analysis for the system and assuming $V_{1}=V_{11}$ and $Z_{1}=Z_{11}$ (Fig. 1), the objective function is assembled as shown in Eq. (21). The function to be maximised (the objective function), is $\dot{W}_{n e t}$ (the net power output). Eq. (22) shows the total entropy generation rate in terms of the temperatures and pressures (with reference to Fig. 1). The entropy generation rate for each component is added and is shown in block brackets.

$$
\dot{W}_{n e t}=-T_{0} \dot{S}_{g e n, \mathrm{int}}+\left(1-T_{0} / T *\right) \dot{Q}^{*}+\dot{m} c_{p 0}\left(T_{1}-T_{11}\right)-\dot{m} T_{0} c_{p 0} \ln \left(T_{1} / T_{11}\right)
$$

where

$$
\begin{aligned}
& \dot{S}_{\text {gen }, \mathrm{int}}=\left\lfloor-\dot{m} c_{p 0} \ln \left(T_{1} / T_{2}\right)+\dot{m} R \ln \left(P_{1} / P_{2}\right)\right]_{\text {compressor }}+\left[\dot{Q}_{l} / T_{0}+\dot{m} c_{p 0} \ln \left(T_{3} / T_{2}\right)-\dot{m} R \ln \left(P_{3} / P_{2}\right)\right]_{\text {Duct } 23} \\
& +\left[\dot{m} c_{p 0} \ln \left[\frac{T_{10} T_{4}}{T_{9} T_{3}}\left(\frac{P_{10} P_{4}}{P_{9} P_{3}}\right)^{-R / c_{p 0}}\right]+\dot{Q}_{l} / T_{0}\right]_{\text {recuperator }}+\left[\dot{Q}_{l} / T_{0}+\dot{m} c_{p 0} \ln \left(T_{5} / T_{4}\right)-\dot{m} R \ln \left(P_{5} / P_{4}\right)\right]_{\text {Duct } 45} \\
& +\left[-\frac{\dot{Q}^{*}}{T^{*}}+\frac{\dot{Q}_{\text {loss }}}{T_{0}}+\dot{m} c_{p 0} \ln \left(T_{6} / T_{5}\right)-\dot{m} R \ln \left(P_{6} / P_{5}\right)\right]_{\text {receiver }}+\left[\dot{Q}_{l} / T_{0}+\dot{m} c_{p 0} \ln \left(T_{7} / T_{6}\right)-\dot{m} R \ln \left(P_{7} / P_{6}\right)\right]_{\text {Duct } 67} \\
& +\left[-\dot{m} c_{p 0} \ln \left(T_{7} / T_{8}\right)+\dot{m} R \ln \left(P_{7} / P_{8}\right)\right]_{\text {turbine }}+\left[\dot{Q}_{l} / T_{0}+\dot{m} c_{p 0} \ln \left(T_{9} / T_{8}\right)-\dot{m} R \ln \left(P_{9} / P_{8}\right)\right]_{\text {Duct89 }}
\end{aligned}
$$

Note that $\dot{Q}^{*}-\dot{Q}_{\text {loss }}=\dot{Q}_{\text {net }}$.

\subsubsection{Constraints}

The recuperator channel aspect ratio is constrained to a maximum of 100 . The ratio between concentrator area and receiver aperture area is constrained to 100. 
$D_{\text {rec }} L_{\text {rec }} / 8-A_{s, \text { conc }} / 100 \leq 0$

Eq. (24) prevents the receiver from losing its cavity shape, by only allowing a minimum of two diameters in the distance between the aperture edge and the edge of the receiver.

$$
2 D_{\text {rec }}-((\sqrt{3}-1) / 2) \sqrt{D_{\text {rec }} L_{\text {rec }} / 2 \pi} \leq 0
$$

The cavity receiver tube is constructed from copper. The maximum surface temperature of the receiver tube should stay well below its melting temperature. An allowable maximum receiver surface temperature of $T_{s, \max }$ is identified for the analysis [22, 32]. The surface area of a tube and the Dittus-Boelter equation [33] help to construct Eq. (25), which is the maximum surface temperature of the receiver.

$$
T_{s, \max }=T_{6}+\frac{\dot{Q}_{n e t}}{0.023 \pi L_{r e c} k \operatorname{Pr}^{0.4}\left(4 \dot{m} /\left(\mu \pi D_{\text {rec }}\right)\right)^{0.8}}
$$

The longer the recuperator the more beneficial it is to the system. There needs to be a constraint on its length. To make sure the system stays compact, the recuperator's length should not exceed the length of the radius of the dish,

$$
L_{\text {reg }} \leq D_{\text {conc }} / 2
$$

\section{Research methodology}

There are five geometric variables to be optimised: The cavity receiver tube diameter, $D_{\text {rec }}$, the tube length of the cavity receiver, $L_{\text {rec }}$, the hydraulic diameter of the recuperator channels, $D_{h, \text { reg }}$, the length of the recuperator channels, $L_{r e g}$, and aspect ratio of the recuperator channels, $a / b_{\text {reg }}$. The objective function (net power output of the system) in terms of the scaled geometry variables, parameters and constants is maximised using the dynamic trajectory optimisation method by Snyman [34] in MATLAB, with unit step size and convergence tolerance of $1 \times 10^{-4}$. Data points were created at different turbine operating points of the micro-turbine in increments of 0.0625 (for the turbine pressure ratio). Each data point represents an optimised system - a system with maximum net power output and optimised receiver and recuperator geometries.

In Table 1 different conditions and parameters are given. The effect on the system, when each of these conditions or parameters is changed individually, is investigated. The values used as default and values used for inspection are given. When one of the conditions or parameters is inspected, the others are fixed to their default values.

Table 1. Values used for default analysis and for inspection.

\begin{tabular}{|l|l|l|l|}
\hline Environmental condition or parameter & Symbol & Default & Inspected value \\
\hline Surrounding temperature & $T_{0}$ & $300 \mathrm{~K}$ & $288 \mathrm{~K}$ \\
\hline Solar beam irradiance & $I$ & $1000 \mathrm{~W} / \mathrm{m}^{2}$ & $800 \mathrm{~W} / \mathrm{m}^{2}$ \\
\hline Wind speed & $w$ & $0 \mathrm{~m} / \mathrm{s}$ & $10 \mathrm{~m} / \mathrm{s}$ \\
\hline Concentrator error & $e_{p}$ & $0.0067 \mathrm{rad}$ & $0.035 \mathrm{rad}$ \\
\hline Maximum receiver surface temperature & $T_{s, \max }$ & $1200 \mathrm{~K}$ & $1100 \mathrm{~K}$ \\
\hline Concentrator specular reflectivity & $\mathrm{refl}$ & 0.85 & 0.93 \\
\hline
\end{tabular}

The effects of wind and solar beam irradiance are investigated further by maximising the objective function at solar beam irradiance values of $500-1100 \mathrm{~W} / \mathrm{m}^{2}$ (in increments of $100 \mathrm{~W} / \mathrm{m}^{2}$ ) and wind speed values of $0-12 \mathrm{~m} / \mathrm{s}$ (in increments of $2 \mathrm{~m} / \mathrm{s}$ ) respectively.

\section{Results}

Fig. 5 shows the maximum net power output of the system using default values (Table 1) as a function of system mass flow rate. Note that these data points were found by maximising the objective function at different parameter values (turbine pressure ratio in increments of 0.0625). Each data point represents a system with optimised receiver and recuperator and therefor also, the maximum net power output. The minimum internal and external irreversibility rates are also included in Fig. 5. The external irreversibility rate is calculated using Eq. (27). 
$\dot{I}_{e x t}=-\dot{m} c_{p 0}\left(T_{1}-T_{11}\right)+\dot{m} T_{0} c_{p 0} \ln \left(T_{1} / T_{11}\right)$

Note that in Fig. 5, a point of highest maximum net power output exists. This is the optimum operating point of the micro-turbine (in terms of system mass flow rate) for the default values in Table 1. This point of highest maximum net power output corresponds to the point of lowest total minimum irreversibility rate. The maximum net heat rate absorbed by the receiver is also shown.

In Fig. 6 the net power output as calculated in this paper (second law) is compared with the net power output as calculated with the first law of thermodynamics as shown in Eq. (28). These results correlate well.

$$
\dot{W}_{n e t}=\dot{m} c_{p 0}\left(T_{7}-T_{8}\right)-\dot{m} c_{p 0}\left(T_{2}-T_{1}\right)
$$

In Fig. 7 the maximum net power output as shown in Fig. 5 is compared with conditions and parameters other than the default. One can see the effect of various conditions and parameters as they were changed individually to their inspected value as shown in Table 1. Note that the other conditions and parameters stayed default while an individual condition or parameter was investigated. Fig. 7 shows that a smaller allowable receiver surface temperature results in a smaller maximum net power output. Also, a decrease in surrounding temperature increases the maximum net power output. This result confirms that a decrease in the lowest temperature in the cycle and an increase in the highest temperature in the cycle, increase the maximum net power output. This result was also found for the supercritical $\mathrm{CO}_{2}$ recompression Brayton cycle [10].

Fig. 7 further shows that increased wind speed, increased concentrator error and decreased solar beam irradiance, decrease the highest maximum net power output. Note that for each of these conditions also, the optimum operating point of the micro-turbine (in terms of system mass flow rate) is lower than it is for the default. Similarly, as the specular reflectance of the concentrator dish increases, the optimum operating point (in terms of system mass flow rate) and highest maximum net power output increases.

Table 2. Optimum operating point, optimum geometries and highest maximum net power output for different solar beam irradiance scenarios.

\begin{tabular}{|c|c|c|c|c|c|c|c|}
\hline $\begin{array}{c}\boldsymbol{I} \\
\left(\mathbf{W} / \mathbf{m}^{2}\right)\end{array}$ & $\boldsymbol{r}_{\text {t,opt }}$ & $\begin{array}{c}\boldsymbol{D}_{\text {rec,opt }} \\
(\mathbf{c m})\end{array}$ & $\begin{array}{c}\boldsymbol{L}_{\text {rec,opt }} \\
(\mathbf{m})\end{array}$ & $(\boldsymbol{a} / \mathbf{b})_{\text {reg,opt }}$ & $\begin{array}{c}\boldsymbol{D}_{\text {h,reg,opt }} \\
(\mathbf{m m})\end{array}$ & $\begin{array}{c}\boldsymbol{L}_{\text {reg,opt }} \\
(\mathbf{m})\end{array}$ & $\dot{W}_{\text {net,max,max }}(\mathbf{W})$ \\
\hline 500 & 1.5625 & 4.88 & 9.16 & 58.4 & 3.61 & 2.40 & 2960 \\
\hline 600 & 1.625 & 5.53 & 10.38 & 41.4 & 3.96 & 2.40 & 3483 \\
\hline 700 & 1.75 & 5.13 & 9.62 & 94.7 & 3.60 & 2.40 & 4284 \\
\hline 800 & 1.8125 & 6.04 & 11.32 & 53.6 & 4.10 & 2.40 & 4742 \\
\hline 900 & 1.9375 & 5.67 & 10.63 & 100.0 & 3.78 & 2.40 & 5152 \\
\hline $\mathbf{1 0 0 0}$ & $\mathbf{2}$ & $\mathbf{6 . 0 5}$ & $\mathbf{1 1 . 3 5}$ & $\mathbf{9 3 . 8}$ & $\mathbf{3 . 9 3}$ & $\mathbf{2 . 4 0}$ & $\mathbf{5 6 1 4}$ \\
\hline 1100 & 2.0625 & 5.69 & 10.68 & 62.5 & 4.20 & 2.40 & 5830 \\
\hline
\end{tabular}

Table 3. Operating conditions for optimum performance of the system during different solar beam irradiance scenarios.

\begin{tabular}{|c|c|c|c|c|c|}
\hline $\begin{array}{c}\boldsymbol{I} \\
\left(\mathbf{W} / \mathbf{m}^{2}\right)\end{array}$ & $\dot{m}_{\text {opt }}(\mathbf{k g} / \mathbf{s})$ & $\boldsymbol{r}_{\text {opt }}$ & $\eta_{c, \text { opt }}$ & $\dot{Q}_{\text {max } \max }(\mathbf{W})$ & $T_{\text {s, max }, \text { opt }}(\mathbf{W})$ \\
\hline 500 & 0.0484 & 1.62 & 0.635 & 6958 & 1200 \\
\hline 600 & 0.0526 & 1.68 & 0.641 & 8344 & 1200 \\
\hline 700 & 0.0583 & 1.81 & 0.653 & 9867 & 1200 \\
\hline 800 & 0.0611 & 1.86 & 0.654 & 11217 & 1200 \\
\hline 900 & 0.0678 & 1.99 & 0.655 & 12736 & 1169 \\
\hline $\mathbf{1 0 0 0}$ & $\mathbf{0 . 0 7 0 2}$ & $\mathbf{2 . 0 5}$ & $\mathbf{0 . 6 3 0}$ & $\mathbf{1 4 1 5 6}$ & $\mathbf{1 2 0 0}$ \\
\hline 1100 & 0.0734 & 2.13 & 0.628 & 15674 & 1199 \\
\hline
\end{tabular}

The effects of wind and solar beam irradiance are investigated further. In Table 2, the optimum operating point of the micro-turbine and optimum receiver and recuperator geometries, for different solar beam irradiance cases are shown. Note that the data obtained for the highest maximum net power output as shown in Fig. 5, is also shown in bold in Table 2 and Table 3. In Table 3, the optimum operating conditions are shown. The optimum compressor pressure ratio increases as the solar beam irradiance increases. This is also shown in Fig. 8 as a function of system mass flow rate. The highest maximum net power output and optimum system mass flow rate decrease almost linearly.

In Table 4, the optimum operating point of the micro-turbine and optimum receiver and recuperator geometries, for different wind speed scenarios are shown. Note that the data obtained for the highest maximum net power output as shown in Fig. 5, is also shown in bold in Table 4 and Table 5. In Table 5, the optimum operating conditions are shown. Note how the net power output decreases as the wind speed increases. From Table 2 and Table 4 it is shown that the length of the recuperator is always at its maximum when the system operates at its highest maximum net power output. 
Table 4. Optimum operating point, optimum geometries and highest maximum net power output for different wind speed scenarios.

\begin{tabular}{|c|c|c|c|c|c|c|c|}
\hline $\begin{array}{c}\boldsymbol{w} \\
(\mathbf{m} / \mathbf{s})\end{array}$ & $\boldsymbol{r}_{t, o p t}$ & $\begin{array}{c}\boldsymbol{D}_{\text {rec,opt }} \\
(\mathbf{c m})\end{array}$ & $\begin{array}{c}\boldsymbol{L}_{\text {rec,opt }} \\
(\mathbf{m})\end{array}$ & $(\boldsymbol{a} / \mathbf{b})_{\text {reg,opt }}$ & $\begin{array}{c}\boldsymbol{D}_{\text {h,reg,opt }} \\
(\mathbf{m m})\end{array}$ & $\begin{array}{c}\boldsymbol{L}_{\text {reg,opt }} \\
(\mathbf{m})\end{array}$ & $\dot{W}_{\text {net,max,max }}(\mathbf{W})$ \\
\hline 0 & $\mathbf{2}$ & $\mathbf{6 . 0 5}$ & $\mathbf{1 1 . 3 5}$ & $\mathbf{9 3 . 8}$ & $\mathbf{3 . 9 3}$ & $\mathbf{2 . 4 0}$ & $\mathbf{5 6 1 4}$ \\
\hline 2 & 1.875 & 5.27 & 10.17 & 26.4 & 6.76 & 2.40 & 4980 \\
\hline 4 & 1.9375 & 4.27 & 8.00 & 46.8 & 4.41 & 2.40 & 4770 \\
\hline 6 & 1.875 & 4.34 & 8.15 & 26.7 & 4.87 & 2.36 & 4683 \\
\hline 8 & 1.9375 & 3.74 & 7.02 & 57.5 & 3.94 & 2.40 & 4404 \\
\hline 10 & 1.8125 & 4.26 & 7.99 & 24.8 & 8.15 & 2.40 & 4337 \\
\hline 12 & 1.75 & 4.31 & 8.09 & 22.7 & 11.65 & 2.40 & 4016 \\
\hline
\end{tabular}

Table 5. Operating conditions for optimum performance of the system during different wind speed scenarios.

\begin{tabular}{|c|c|c|c|c|c|}
\hline $\begin{array}{c}\boldsymbol{w} \\
(\mathbf{m} / \mathbf{s})\end{array}$ & $\dot{m}_{\text {opt }}(\mathbf{k g} / \mathbf{s})$ & $\boldsymbol{r}_{\text {opt }}$ & $\eta_{c, \text { opt }}$ & $\dot{Q}_{\max , \max }(\mathbf{W})$ & $T_{s, \max , \text { opt }}(\mathbf{W})$ \\
\hline $\mathbf{0}$ & $\mathbf{0 . 0 7 0 2}$ & $\mathbf{2 . 0 5}$ & $\mathbf{0 . 6 3 0}$ & $\mathbf{1 4 1 5 6}$ & $\mathbf{1 2 0 0}$ \\
\hline 2 & 0.0640 & 1.94 & 0.653 & 13431 & 1200 \\
\hline 4 & 0.0673 & 2.05 & 0.627 & 13501 & 1199 \\
\hline 6 & 0.0643 & 1.98 & 0.649 & 13129 & 1201 \\
\hline 8 & 0.0673 & 2.10 & 0.623 & 13280 & 1199 \\
\hline 10 & 0.0613 & 1.91 & 0.650 & 12608 & 1200 \\
\hline 12 & 0.0586 & 1.84 & 0.651 & 12278 & 1200 \\
\hline
\end{tabular}

In Table 6, the optimum temperatures and pressures are shown for the system (see Fig. 1) as it operates at the various solar beam irradiance cases. Note that the optimum exhaust temperature, $T_{10}$, increases almost linearly as the solar beam irradiance increases. This is also shown in Fig. 9. When the solar beam irradiance increases from $500 \mathrm{~W} / \mathrm{m}^{2}$ to $900 \mathrm{~W} / \mathrm{m}^{2}$, the temperatures, $T_{4}, T_{5}, T_{6}, T_{7}, T_{8}$ and $T_{9}$, decrease (Table 6). The air temperature increase in the receiver is a function of the solar beam irradiance as shown in Fig. 10. Also note how the pressures $P_{2}, P_{3}$, $P_{4}, P_{5}, P_{6}$ and $P_{7}$ increase as the solar beam irradiance increases (Table 6).

Table 6. Optimum temperatures and pressures of the system at different solar beam irradiance scenarios.

\begin{tabular}{|c|c|c|c|c|c|c|c|}
\hline $\begin{array}{c}I \\
\left(\mathbf{W} / \mathbf{m}^{2}\right)\end{array}$ & 500 & 600 & 700 & 800 & 900 & 1000 & 1100 \\
\hline$T_{1}(\mathbf{K})$ & 300 & 300 & 300 & 300 & 300 & 300 & 300 \\
\hline$T_{2}(\mathbf{K})$ & 370 & 374 & 385 & 389 & 400 & 408 & 415 \\
\hline$T_{3}(\mathbf{K})$ & 368 & 372 & 383 & 387 & 398 & 406 & 413 \\
\hline$T_{4}(\mathbf{K})$ & 1030 & 1013 & 998 & 982 & 944 & 959 & 942 \\
\hline$T_{5}(\mathbf{K})$ & 1028 & 1011 & 996 & 980 & 942 & 957 & 940 \\
\hline$T_{6}(\mathbf{K})$ & 1154 & 1149 & 1144 & 1141 & 1106 & 1133 & 1127 \\
\hline$T_{7}(\mathbf{K})$ & 1152 & 1147 & 1142 & 1139 & 1104 & 1131 & 1125 \\
\hline$T_{8}(\mathbf{K})$ & 1040 & 1027 & 1006 & 995 & 952 & 967 & 956 \\
\hline$T_{9}(\mathbf{K})$ & 1038 & 1025 & 1004 & 993 & 950 & 965 & 954 \\
\hline$T_{10}(\mathrm{~K})$ & 376 & 385 & 389 & 398 & 404 & 413 & 424 \\
\hline$P_{I}(\mathrm{~Pa})$ & 86000 & 86000 & 86000 & 86000 & 86000 & 86000 & 86000 \\
\hline$P_{2}(\mathbf{P a})$ & 139462 & 144140 & 155705 & 159948 & 171393 & 176325 & 182762 \\
\hline$P_{3}(\mathrm{~Pa})$ & 139323 & 143996 & 155550 & 159788 & 171222 & 176149 & 182579 \\
\hline$P_{4}(\mathrm{~Pa})$ & 139179 & 143815 & 155460 & 159663 & 171144 & 176073 & 182455 \\
\hline $\boldsymbol{P}_{5}(\mathbf{P a})$ & 138624 & 143242 & 154840 & 159027 & 170462 & 175372 & 181728 \\
\hline$P_{6}(\mathrm{~Pa})$ & 135504 & 141059 & 151611 & 157177 & 167836 & 173246 & 178935 \\
\hline$P_{7}(\mathbf{P a})$ & 134964 & 140497 & 151007 & 156551 & 167168 & 172556 & 178222 \\
\hline$P_{8}(\mathbf{P a})$ & 86377 & 86459 & 86290 & 86373 & 86280 & 86278 & 86411 \\
\hline$P_{9}(\mathrm{~Pa})$ & 86291 & 86373 & 86204 & 86287 & 86194 & 86192 & 86324 \\
\hline $\begin{array}{c}P_{10} \\
(\mathbf{P a})\end{array}$ & 86000 & 86000 & 86000 & 86000 & 86000 & 86000 & 86000 \\
\hline
\end{tabular}

In Table 7, the optimum temperatures and pressures are shown for the system (see Fig. 1) as it is operating at the various wind speed scenarios. Note that the optimum exhaust temperature, $T_{10}$, increases slightly as the wind speed increases. This is shown in Fig. 9. The optimum system mass flow rate decreases as the wind speed increases to $12 \mathrm{~m} / \mathrm{s}$. Similarly, in Fig. 10, the optimum receiver air temperature difference increases slightly as the wind speed increases.

The method in this paper can be used to determine the best geometries of the receiver and recuperator for the various weather conditions it will be operating in mostly. Figure 11 shows that a system with a set of fixed geometries from Table 2, performs almost as well at other solar beam irradiance values, as a system with variable geometries. Note that in Fig. 11, the performance of systems with fixed geometries that were optimised for 
$500 \mathrm{~W} / \mathrm{m}^{2}$ and $1100 \mathrm{~W} / \mathrm{m}^{2}$ respectively (see Table 2), are shown. Figure 11 shows that the optimum turbine operating point (system mass flow rate) can be altered so that the system with fixed geometries can perform well. This was done by applying the method of total entropy generation minimisation to determine these optimum system mass flow rates. Figure 11 thus shows the practical application of this technique and shows that the operating point of the micro-turbine plays an important role in obtaining the best power output for the system when operating in an environment with changing weather.

Table 7. Optimum temperatures and pressures of the system at different wind speed scenarios.

\begin{tabular}{|c|c|c|c|c|c|c|c|}
\hline$w(\mathrm{~m} / \mathrm{s})$ & 0 & 2 & 4 & 6 & 8 & 10 & 12 \\
\hline$T_{1}(\mathrm{~K})$ & 300 & 300 & 300 & 300 & 300 & 300 & 300 \\
\hline$T_{2}(\mathbf{K})$ & 408 & 396 & 409 & 400 & 414 & 394 & 388 \\
\hline$T_{3}(\mathrm{~K})$ & 406 & 394 & 407 & 398 & 412 & 392 & 386 \\
\hline$T_{4}(\mathbf{K})$ & 959 & 950 & 955 & 953 & 957 & 951 & 947 \\
\hline$T_{5}(\mathrm{~K})$ & 957 & 948 & 953 & 951 & 955 & 949 & 945 \\
\hline$T_{6}(\mathrm{~K})$ & 1133 & 1131 & 1128 & 1129 & 1128 & 1128 & 1128 \\
\hline$T_{7}(\mathbf{K})$ & 1131 & 1129 & 1126 & 1127 & 1126 & 1126 & 1126 \\
\hline$T_{8}(\mathrm{~K})$ & 967 & 980 & 970 & 978 & 970 & 985 & 992 \\
\hline$T_{9}(\mathrm{~K})$ & 965 & 978 & 968 & 976 & 968 & 983 & 990 \\
\hline$T_{10}(\mathrm{~K})$ & 413 & 421 & 420 & 421 & 422 & 424 & 429 \\
\hline$P_{1}(\mathbf{P a})$ & 86000 & 86000 & 86000 & 86000 & 86000 & 86000 & 86000 \\
\hline$P_{2}(\mathrm{~Pa})$ & 176325 & 166534 & 176377 & 170437 & 180919 & 164366 & 158243 \\
\hline$P_{3}(\mathrm{~Pa})$ & 176149 & 166368 & 176201 & 170266 & 180738 & 164202 & 158085 \\
\hline$P_{4}(\mathrm{~Pa})$ & 176073 & 166305 & 176080 & 170086 & 180605 & 164167 & 158073 \\
\hline$P_{5}(\mathbf{P a})$ & 175372 & 165642 & 175378 & 169408 & 179886 & 163513 & 157443 \\
\hline$P_{6}(\mathrm{~Pa})$ & 173246 & 162339 & 168056 & 162883 & 168127 & 156805 & 151301 \\
\hline$P_{7}(\mathbf{P a})$ & 172556 & 161692 & 167386 & 162234 & 167457 & 156180 & 150699 \\
\hline$P_{8}(\mathrm{~Pa})$ & 86278 & 86236 & 86393 & 86525 & 86429 & 86168 & 86113 \\
\hline$P_{9}(\mathrm{~Pa})$ & 86192 & 86150 & 86307 & 86439 & 86343 & 86082 & 86027 \\
\hline $\begin{array}{l}P_{10} \\
(\mathbf{P a})\end{array}$ & 86000 & 86000 & 86000 & 86000 & 86000 & 86000 & 86000 \\
\hline
\end{tabular}

\section{Conclusion}

The open and direct solar thermal Brayton cycle with a solar dish diameter of $5.2 \mathrm{~m}$ and an off-the-shelf microturbine, should be able to operate optimally in various solar beam irradiance and wind speed scenarios. The method of total entropy generation minimisation was applied to optimise the geometries of a modified cavity receiver and a counterflow plate-type recuperator, at various turbine operating points. This optimisation was done for various solar beam irradiance and wind scenarios. The dynamic trajectory optimisation method for constrained optimisation was used.

Results show that the operating point of the micro-turbine plays an important role in obtaining the best power output for the system when operating in an environment with changing weather. When the solar beam irradiance increases, the turbine pressure ratio increases. The results show the optimum geometries of the receiver and recuperator as a function of the solar beam irriadiance and wind speed. These results can aid in receiver and recuperator design. For a system with a fixed receiver and recuperator geometry, the mass flow rate through the system (turbine operating point) should increase as the solar beam irradiance increases, to allow for the highest net power output.

Results showed that the optimum operating point decreases as the wind speed increases. The optimum exhaust temperature of the system and the optimum air temperature difference in the receiver, decrease as the solar beam irradiance decreases, while for increased wind speed, these temperatures increased slightly. These results can be used in the preliminary stages of design.

The authors specifically investigated the effects of wind and solar irradiance on the optimum performance of the system. The effects of other environmental conditions and constraints, on the maximum net power output, were also investigated. These included surrounding temperature, concentrator error, concentrator reflectivity and maximum allowable surface temperature of the receiver. Results show that a temperature decrease of the surroundings increase the maximum net power output. Increased wind and larger concentrator error decrease the maximum net power output. The lower the maximum allowable receiver surface temperature, the lower the maximum net power output of the system.

Further studies would entail the construction and testing of an experimental model and a comparison of the results with the current approach. 


\section{References}

[1] Chen L, Zhang W, Sun F. Power, efficiency, entropy-generation rate and ecological optimization for a class of generalized irreversible universal heat-engine cycles. Applied Energy 2007; 84: 512-25.

[2] Mills D. Advances in solar thermal electricity technology. Solar Energy 2004; 76: 19-31.

[3] Stine BS, Harrigan RW. Solar energy fundamentals and design. New York: John Wiley; 1985.

[4] Sendhil Kumar N, Reddy KS. Comparison of receivers for solar dish collector system. Energy Conversion and Management 2008; 49: 812-9.

[5] Kaushika ND, Reddy KS. Performance of a low cost solar paraboloidal dish steam generating system. Energy Conversion and Management 2000; 41: 713-26.

[6] Sendhil Kumar N, Reddy KS. Numerical investigation of natural convection heat loss in modified cavity receiver for fuzzy focal solar dish concentrator. Solar Energy 2007; 81: 846-55.

[7] Reddy KS, Sendhil Kumar N. Combined laminar natural convection and surface radiation heat transfer in a modified cavity receiver of solar parabolic dish. International Journal of Thermal Sciences 2008; 47: 1647-57.

[8] Reddy KS, Sendhil Kumar N. An improved model for natural convection heat loss from modified cavity receiver of solar dish concentrator. Solar Energy 2009; 83: 1884-92.

[9] Bejan A. Entropy generation through heat and fluid flow. Colorado: John Wiley; 1982.

[10] Sarkar J. Second law analysis of supercritical CO2 recompression Brayton cycle. Energy 2009; 34: $1172-8$.

[11] Sarkar J. Thermodynamic analyses and optimization of a recompression N2O Brayton power cycle. Energy 2010; 35: 3422-8.

[12] Gupta MK, Kaushik SC. Exergetic performance evaluation and parametric studies of solar air heater. Energy 2008; 33: 1691- 1702

[13] Ameri M, Behbahaninia A, Abbas Tanha A. Thermodynamic analysis of a trigeneration system based on micro-gas turbine with a steam ejector refrigeration system. Energy 2010; 35 :2203-9.

[14] Zimparov VD, Da Silva AK, Bejan A. Thermodynamic optimization of tree-shaped flow geometries with constant channel wall temperature. International Journal of Heat and Mass Transfer 2006; 49: 4839-49.

[15] Zimparov VD, Da Silva AK, Bejan A. Thermodynamic optimization of tree-shaped flow geometries. International Journal of Heat and Mass Transfer 2006; 49: 1619-30.

[16] Bejan A. Method of entropy generation minimization, or modeling and optimization based on combined heat transfer and thermodynamics. Revue Générale de Thermique 1996; 35: 637-46.

[17] Bejan A, Tsatsaronis G, Moran M. Thermal design and optimization. New York: John Wiley; 1996.

[18] Shiba T, Bejan A. Thermodynamic optimization of geometric structure in the counterflow heat exchanger for an environmental control system. Energy 2001; 26: 493-511.

[19] Ordóñez JC, Bejan A. Entropy generation minimization in parallel-plates counterflow heat exchangers. International Journal of Energy Research 2000; 24: 843-64.

[20] Le Roux WG, Bello-Ochende T, Meyer JP. Thermodynamic optimisation of an integrated design of a smallscale solar thermal Brayton cycle. International Journal of Energy Research; 2011. doi:10.1002/er.1859.

[21] Le Roux WG, Bello-Ochende T, Meyer JP. Operating conditions of an open and direct solar thermal Brayton cycle with optimised cavity receiver and recuperator. Energy; 2011. doi:10.1016/j.energy.2011.08.012.

[22] Garrett. Garrett by Honeywell: turbochargers, intercoolers, upgrades, wastegates, blow-off valves, turbotutorials, Available at: http://www.TurboByGarrett.com; 2009. [Accessed 26 April 2010].

[23] Burden RL, Faires JD. Numerical analysis. $8^{\text {th }}$ ed. Youngston State University: Thomson Brooks/Cole; 2005.

[24] Gnielinski V. New equations for heat and mass transfer in turbulent pipe and channel flow. International Chemical Engineering 1976; 16: 359-68.

[25] Petukhov BS. Heat transfer and friction in turbulent pipe flow with variable physical properties. Advances in Heat Transfer 1970; 6.

[26] Çengel YA. Heat and mass transfer. $3^{\text {rd }}$ ed. Nevada, Reno: McGraw-Hill; 2006.

[27] Snyman JA. Practical mathematical optimization. Pretoria: University of Pretoria; 2009.

[28] Wilson DG, Korakianitis T. The design of high-efficiency turbomachinery and gas turbines. 2nd ed. New Jersey: Prentice Hall 1998.

[29] Lidsky LM, Lanning DD, Staudt JE, Yan XL, Kaburaki H, Mori M. A direct-cycle gas turbine power plant for near-term application: MGR-GT. Energy 1991; 16: 177-86.

[30] Zhuge W, Zhang Y, Zheng X, Yang M, He Y. Development of an advanced turbocharger simulation method for cycle simulation of turbocharged internal combustion engines. Proceedings of the Institution of Mechanical Engineers, Part D: Journal of Automobile Engineering 2009; 223: 661. DOI: 10.1243/09544070JAUTO975.

[31] Tveit TM, Savola T, Fogelholm CJ. Modelling of steam turbines for mixed integer nonlinear programming (MINLP) in design and off-design conditions of CHP plant. SIMS 2005; 46: 335-344.

[32] Shah RK. Micro gas turbines, 2, compact heat exchangers for microturbines. Neuilly-sur-Seine, France: RTO, http://www.rto.nato.int/abstracts.asp; 2005.

[33] Dittus FW, Boelter LMK. University of California publications on engineering, vol. 2; 1930. 433 p.

[34] Snyman JA. The LFOPC leap-frog algorithm for constrained optimization. Computers and Mathematics with Applications 2000; 40: 1085-96. 


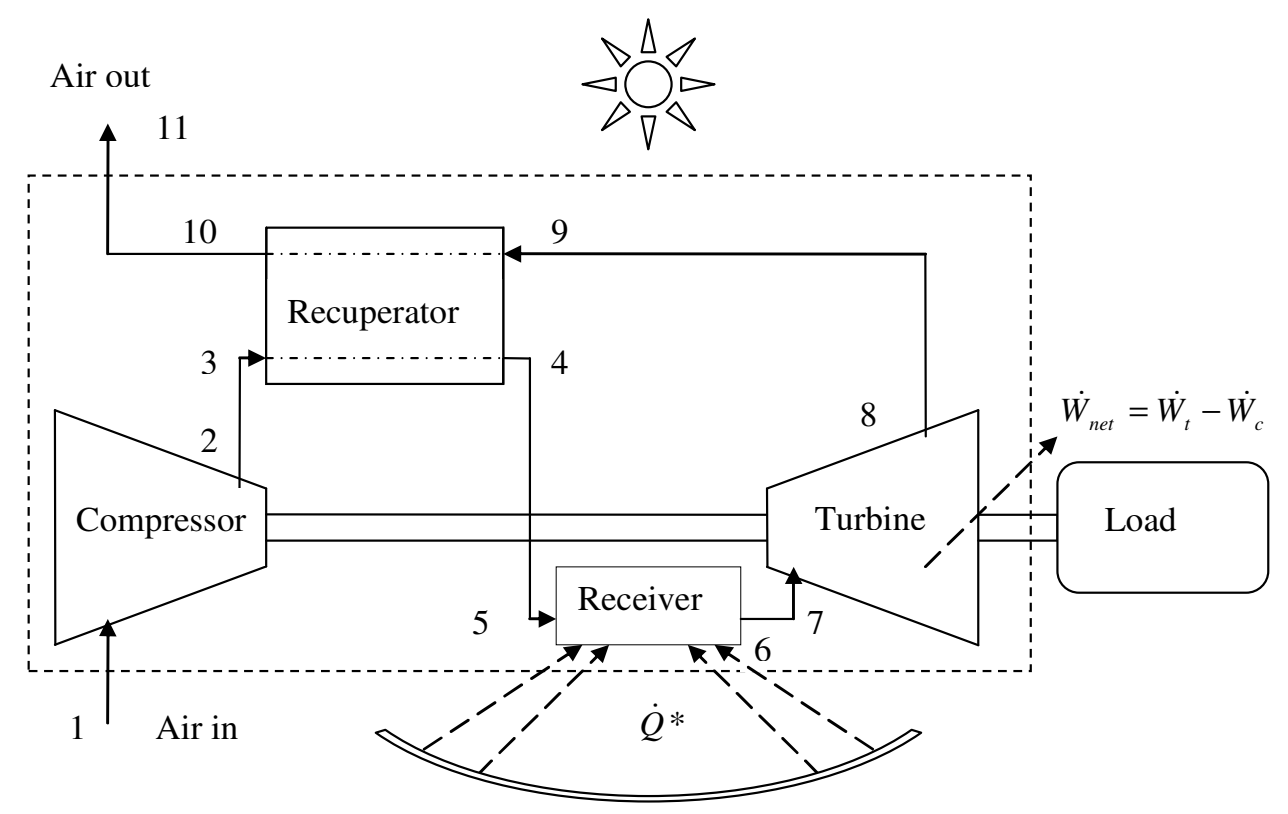

Fig. 1

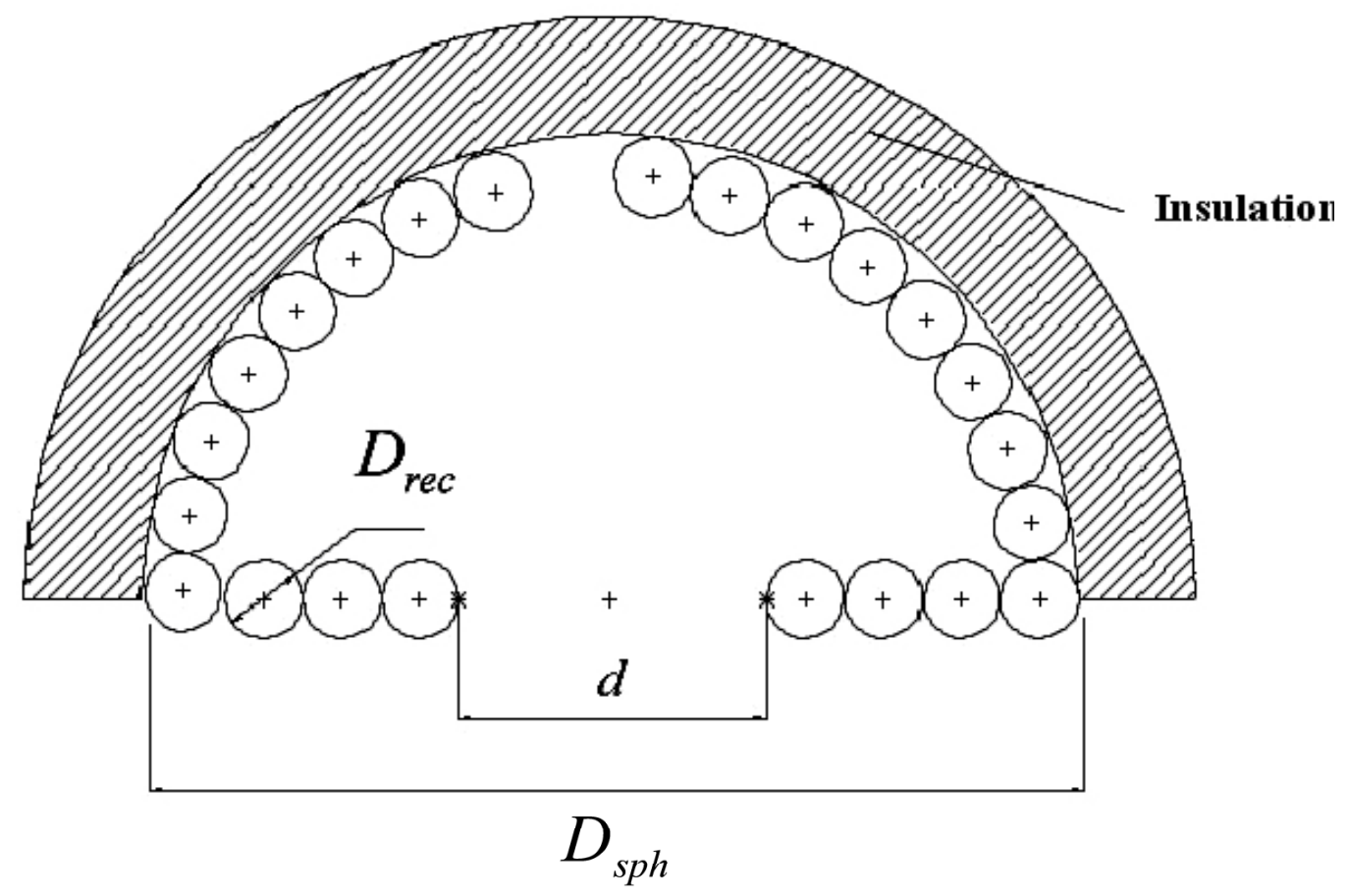

Fig. 2 


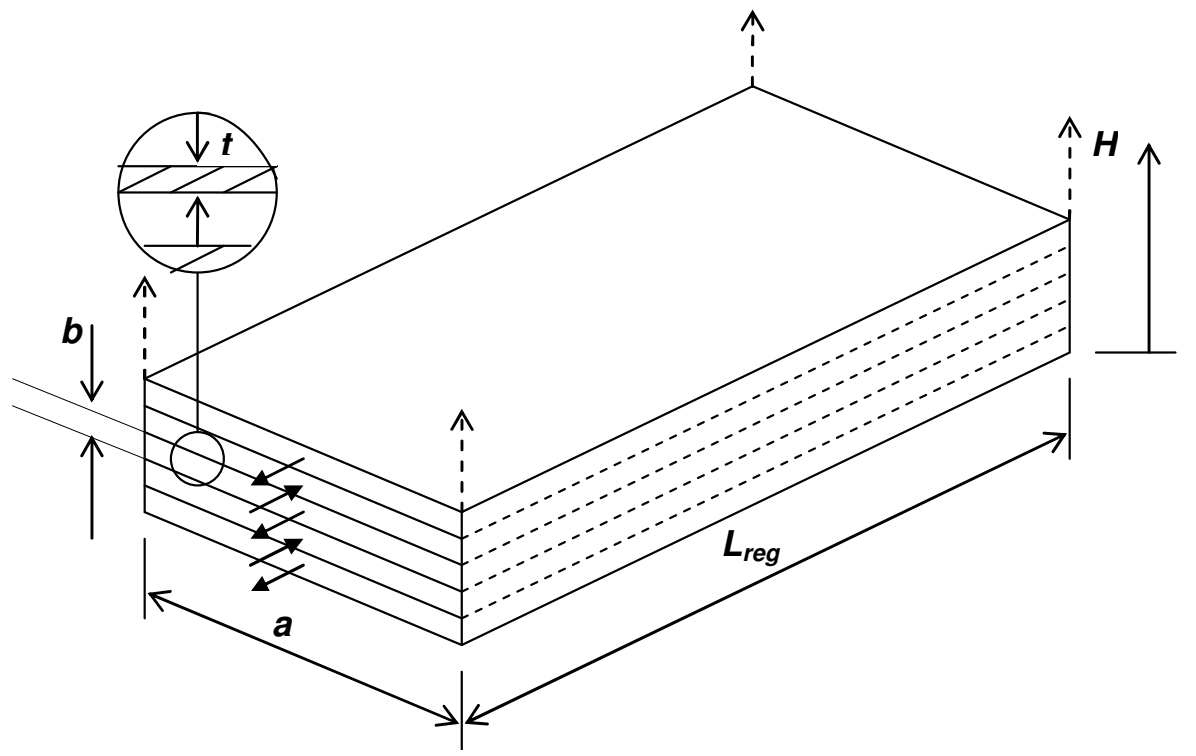

Fig. 3

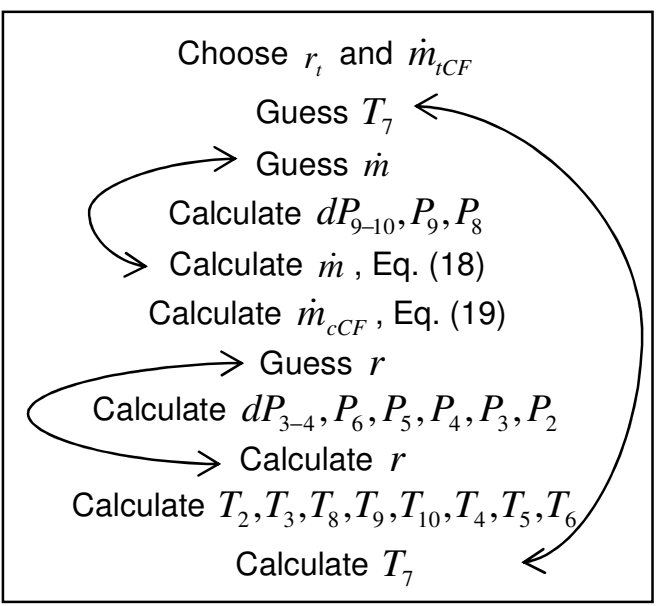

Fig. 4 


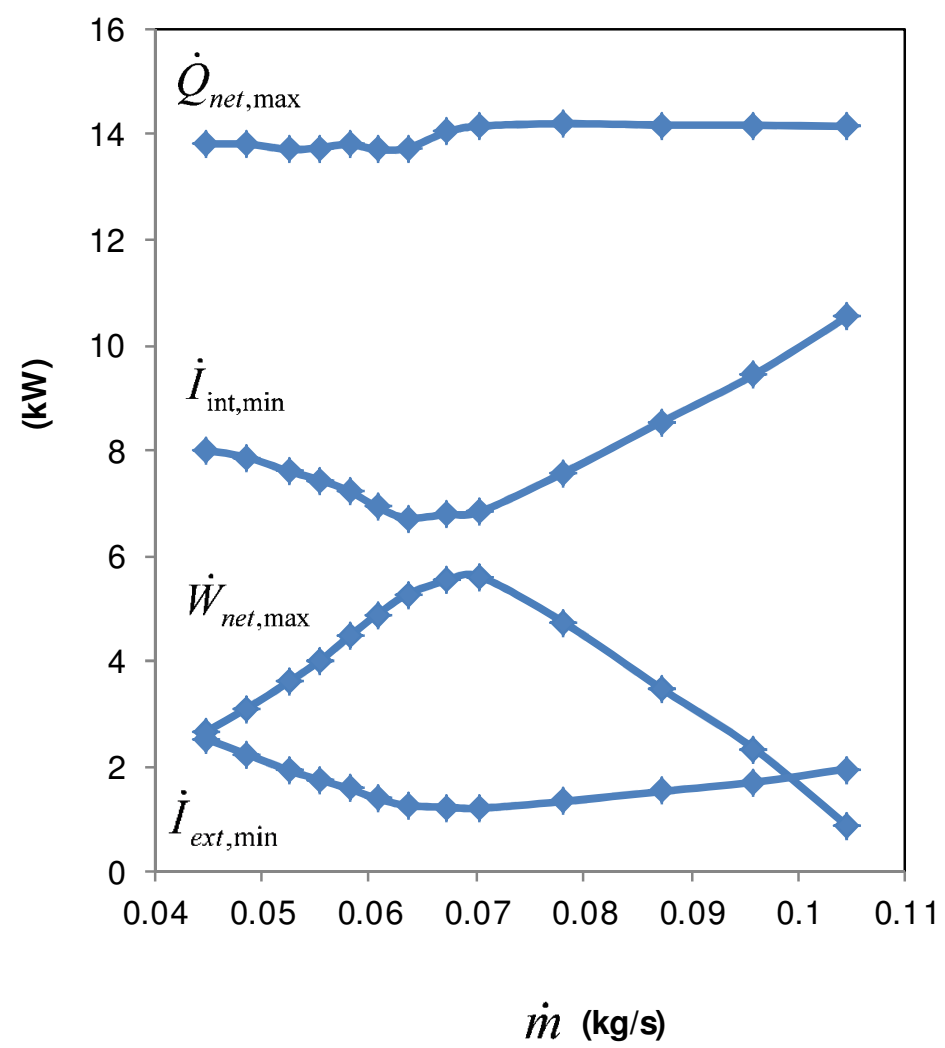

Fig. 5

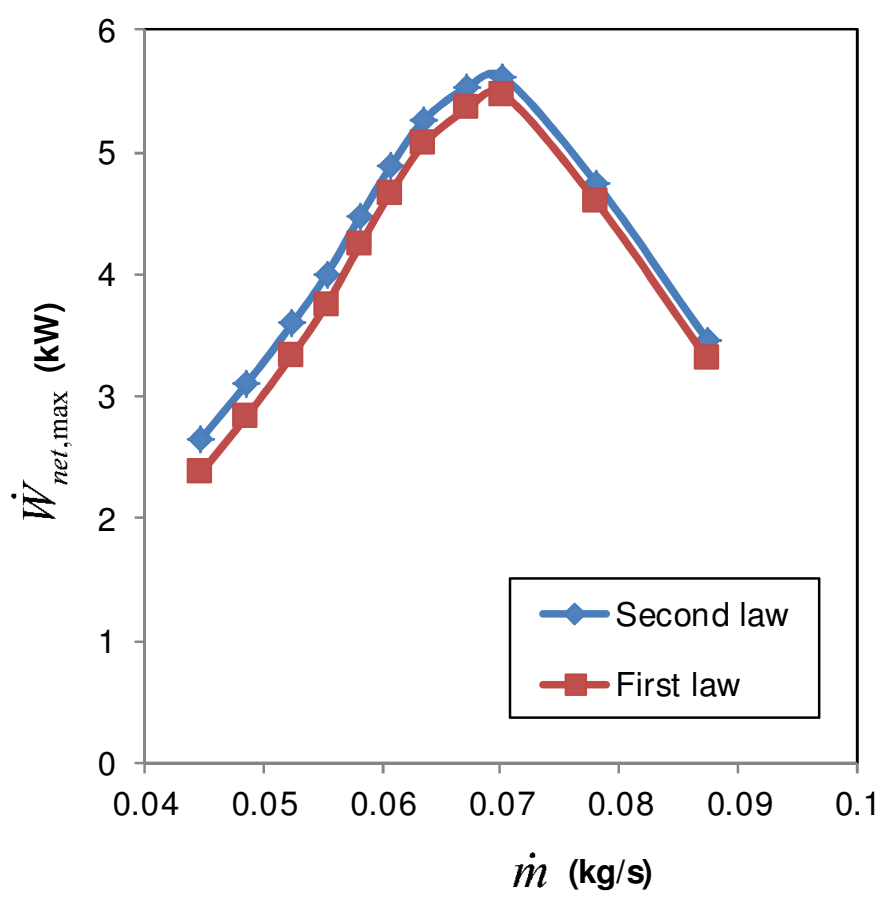

Fig. 6 


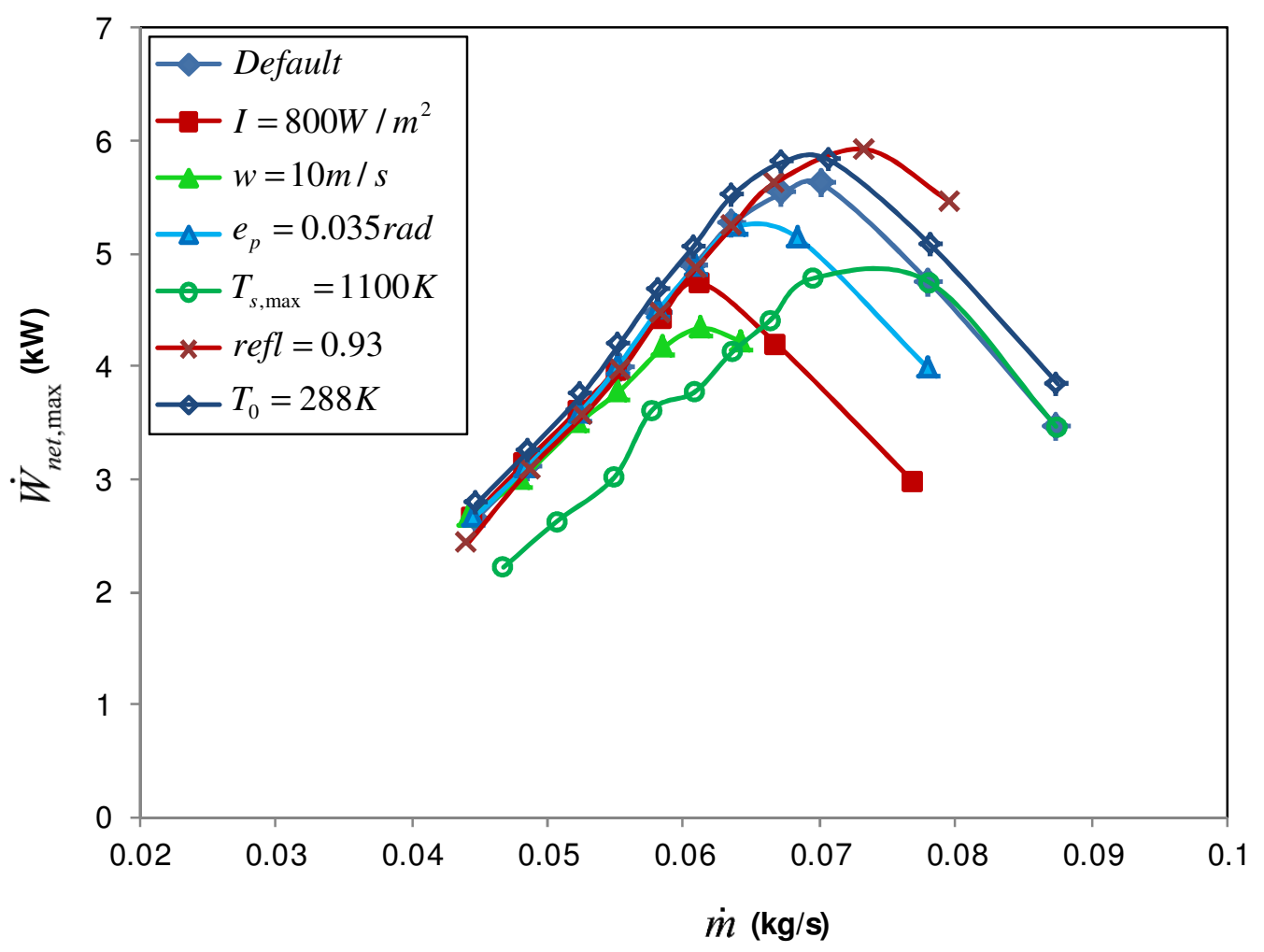

Fig. 7

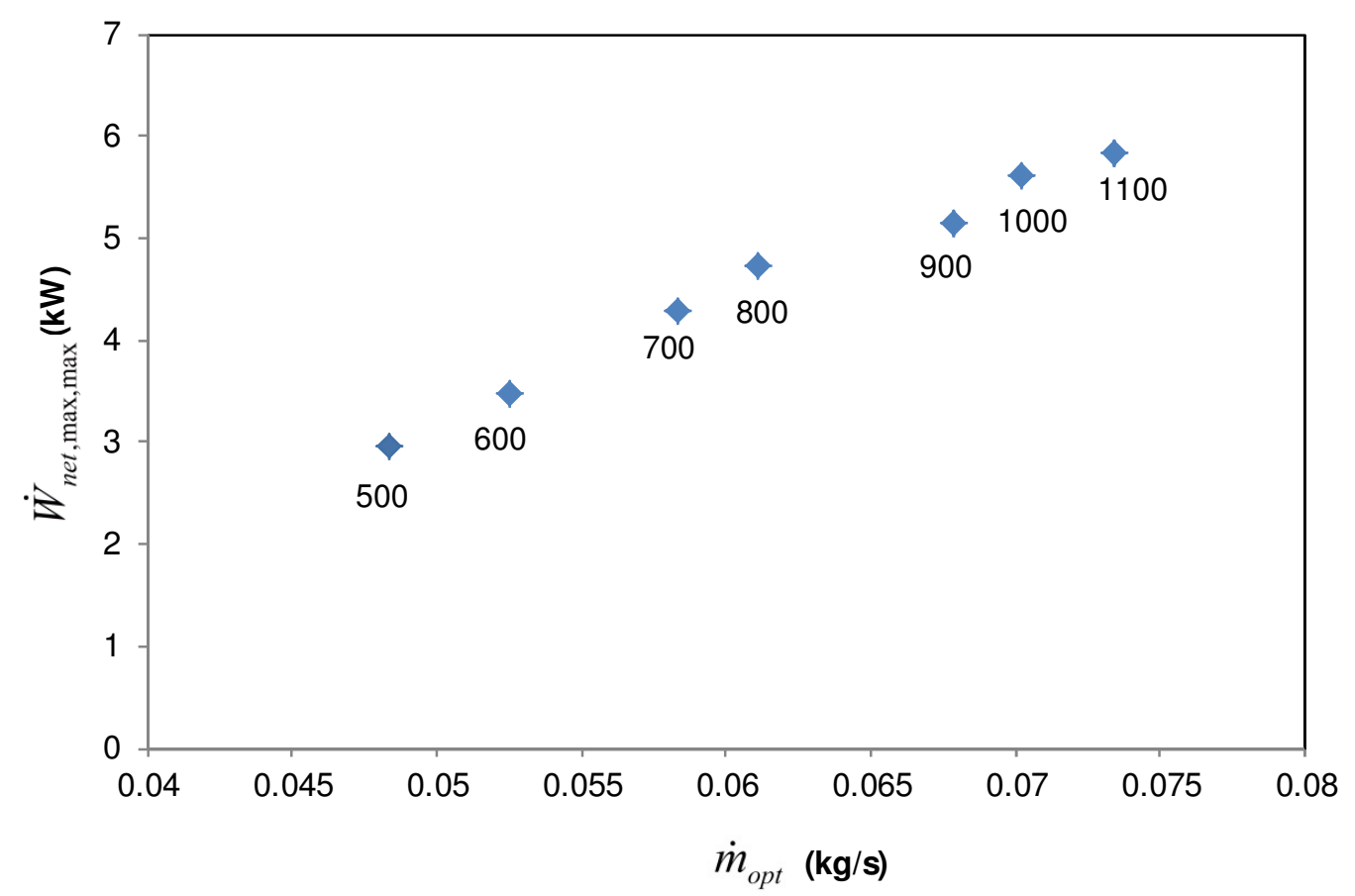

Fig. 8 


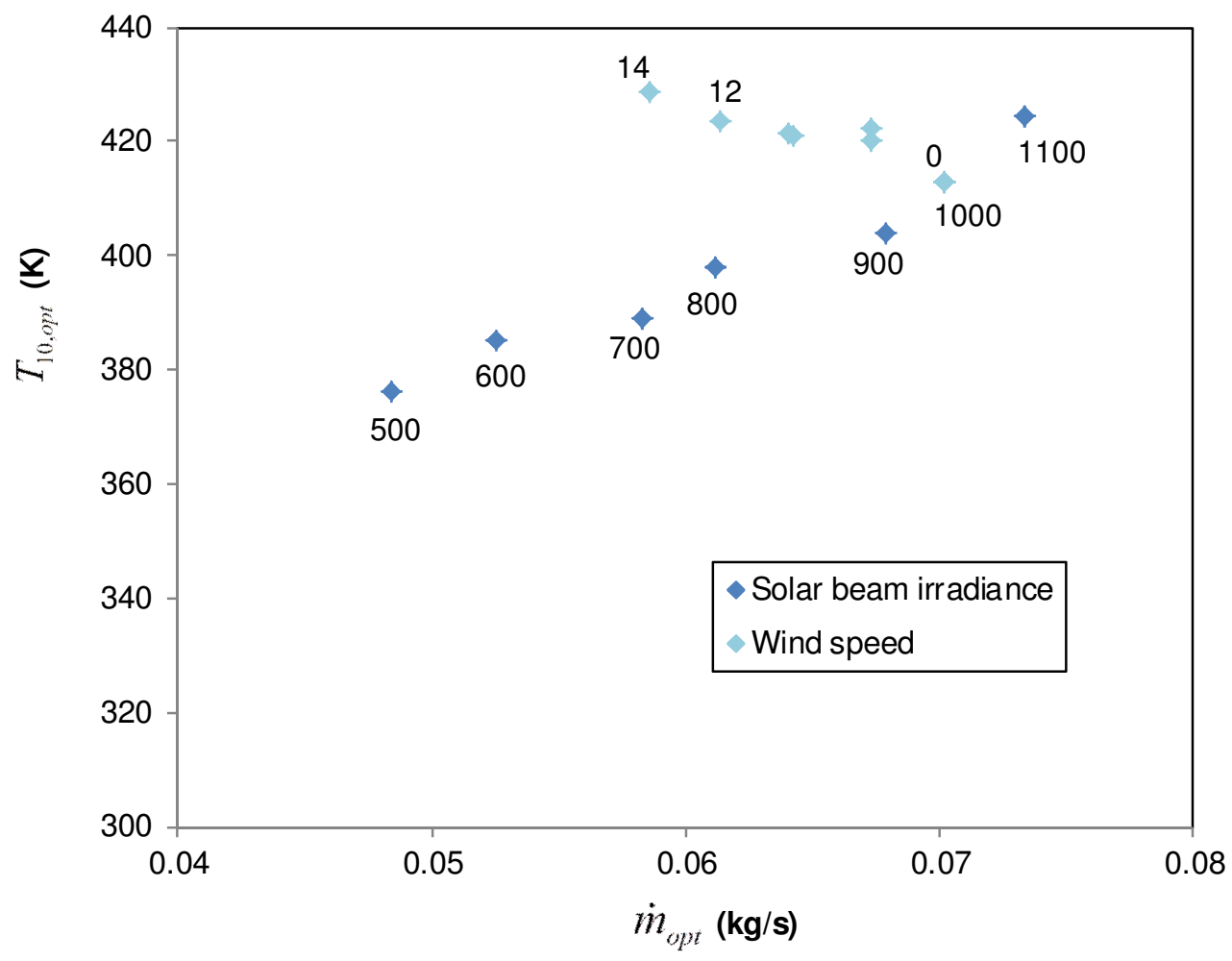

Fig. 9

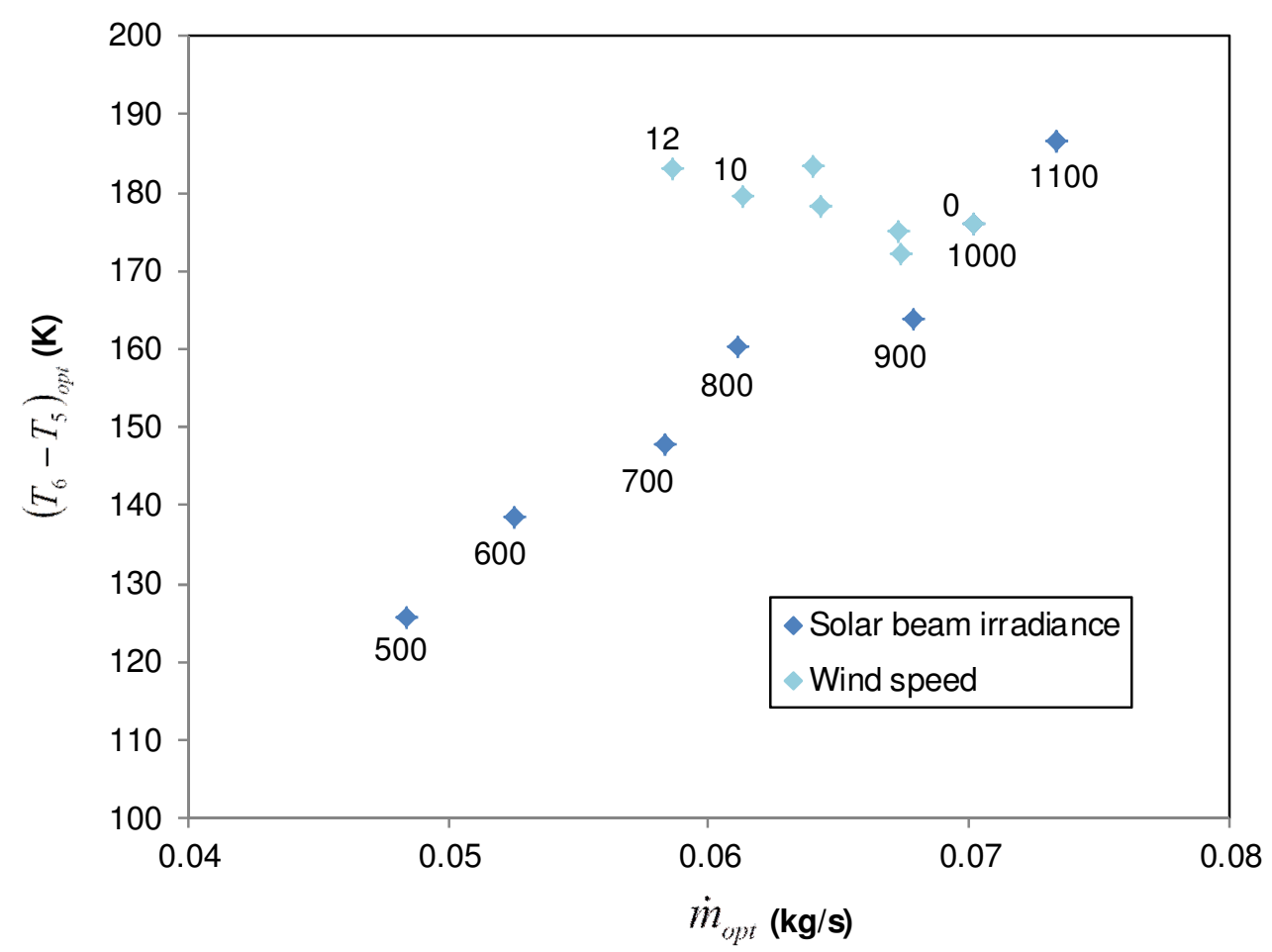

Fig. 10 


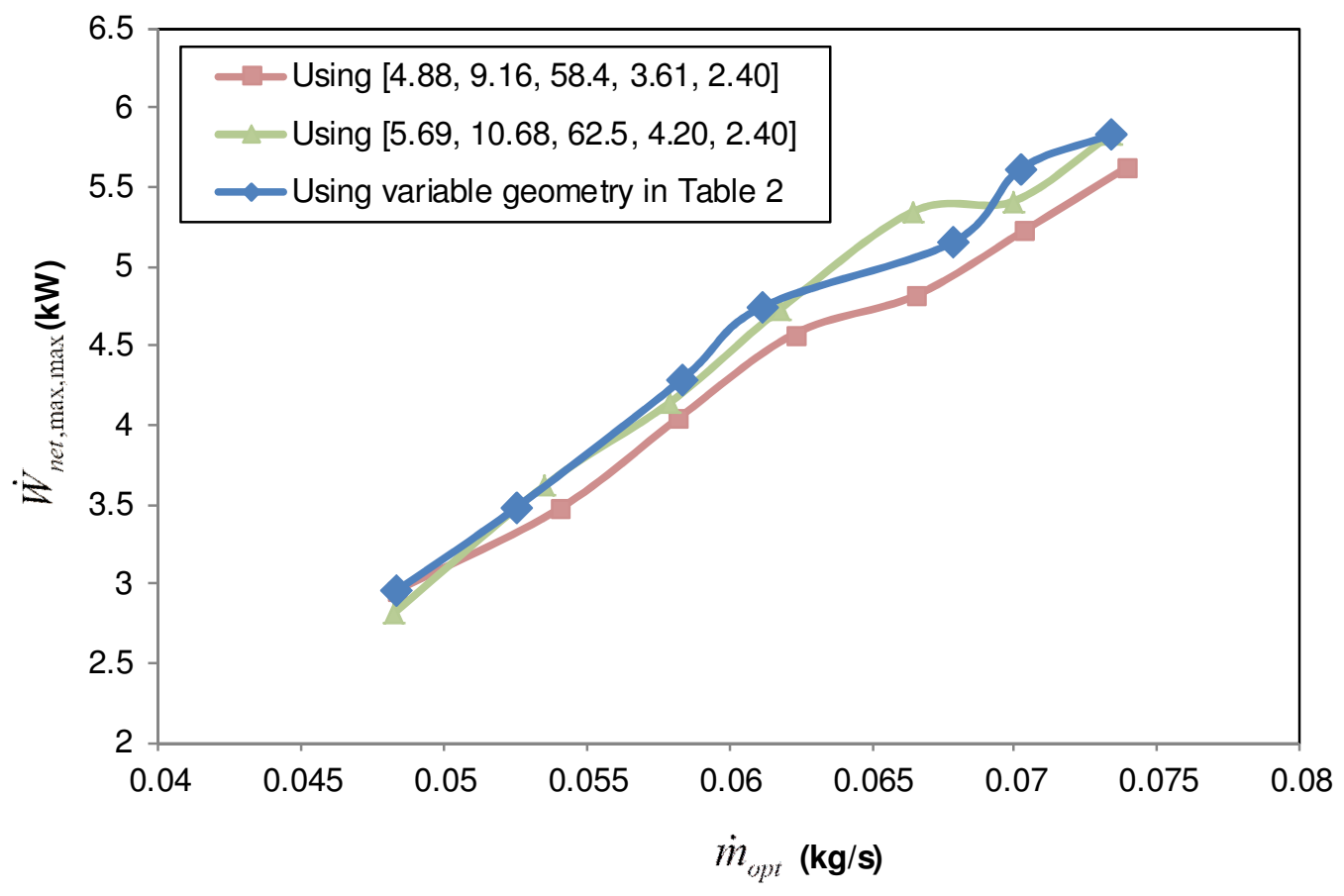

Fig. 11 


\section{Figure captions}

Fig. 1. The open and direct solar thermal Brayton cycle with recuperator.

Fig. 2. Modified solar cavity receiver.

Fig. 3. Counterflow plate-type recuperator.

Fig. 4. Iteration diagram to obtain temperatures and pressures.

Fig. 5. Maximum net power output and minimum irreversibility rates for the system using default values.

Fig. 6. Comparison of net power output calculated with the first and second laws of thermodynamics.

Fig. 7. Maximum net power output at different environmental conditions and parameters.

Fig. 8. Highest maximum net power output at different solar beam irradiance conditions.

Fig. 9. Optimum exhaust air temperature.

Fig. 10. Optimum air temperature increase in the receiver.

Fig. 11. Performance of optimised data sets $\left(\left[D_{r e c}, L_{r e c}, a / b_{r e g}, D_{h, r e g}, L_{r e g}\right]\right)$ 


\section{Nomenclature}

\begin{tabular}{|c|c|c|c|}
\hline$a$ & Longer side of rectangular channel, $\mathrm{m}$ & $y$ & Numerical approximation constant \\
\hline$A$ & 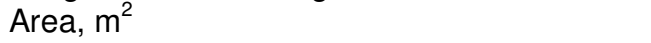 & $Z$ & Height, $m$ \\
\hline$b$ & Shorter side of rectangular channel, $\mathrm{m}$ & & \\
\hline$c_{p 0}$ & Ideal gas specific heat, J/kgK & \multicolumn{2}{|c|}{ Greek Letters } \\
\hline$C$ & Constant, W & $\beta$ & Receiver inclination angle \\
\hline$d$ & Receiver aperture diameter, $\mathrm{m}$ & $\varepsilon$ & Effectiveness (in the $\varepsilon$-NTU method) \\
\hline$d P$ & Change in pressure, $\mathrm{Pa}$ & $\rho$ & Density, $\mathrm{kg} / \mathrm{m}^{3}$ \\
\hline$D$ & Diameter, $\mathrm{m}$ & $\mu$ & Dynamic viscosity, $\mathrm{kg} / \mathrm{ms}$ \\
\hline$e$ & Concentrator error, rad & $\mu$ & Efficiency \\
\hline$f$ & Friction factor & $\eta$ & \\
\hline Gr & Grashof number & & \\
\hline$h$ & Heat transfer coefficient, $\mathrm{W} / \mathrm{m}^{2} \mathrm{~K}$ & \multicolumn{2}{|c|}{ Subscripts } \\
\hline$H$ & Recuperator height, $\mathrm{m}$ & 0 & Environment \\
\hline$I$ & Solar beam irradiance, $\mathrm{W} / \mathrm{m}^{2}$ & $1,2,3 .$. & Refer to Fig. 1 \\
\hline$\dot{I}$ & Rate of irreversibility, W & $a$ & Receiver aperture \\
\hline$k$ & Thermal conductivity, W/mK & $c$ & Compressor \\
\hline$L$ & Length, m & $C F$ & Corrected flow \\
\hline$\dot{m}$ & System mass flow rate, $\mathrm{kg} / \mathrm{s}$ & conc & Parabolic dish concentrator \\
\hline$\dot{m}_{c}$ & Recuperator channel mass flow rate, $\mathrm{kg} / \mathrm{s}$ & $\begin{array}{l}\text { cond } \\
\text { conv }\end{array}$ & $\begin{array}{l}\text { Due to conduction } \\
\text { Due to convection }\end{array}$ \\
\hline$n$ & Number of flow channels & $D$ & Based on internal diameter of channel \\
\hline$N T U$ & Number of transfer units & $D$ & Based on receiver diameter \\
\hline $\mathrm{Nu}$ & Nusselt number & ext & External \\
\hline$P$ & Pressure, Pa & gen & Generation \\
\hline $\operatorname{Pr}$ & Prandtl number & $h$ & Hydraulic \\
\hline$\dot{Q}$ & Heat rate, W & in & At the inlet \\
\hline$\dot{Q}^{*}$ & Rate of intercepted heat at receiver cavity, W & ins & Insulation \\
\hline$\dot{O}_{1}$ & Rate of heat loss from the cavity receiver, $W$ & int & Internal \\
\hline$\dot{Q}_{\text {loss }}$ & Rate of neat loss trom the cavity recelver, vv & $l$ & Loss to environment \\
\hline$\dot{Q}_{n e t}$ & Net rate of absorbed heat, $\mathrm{W}$ & $\max$ & Maximum \\
\hline$r$ & Compressor pressure ratio & $\min$ & Minimum \\
\hline$r_{t}$ & Turbine pressure ratio & net & Net output \\
\hline refl & Specular reflectivity & nrad & Due to natural convection and radiation \\
\hline$R$ & Gas constant, J/kgK & nconv & Due to natural convection \\
\hline $\operatorname{Re}$ & Reynolds number & opt & Optimum \\
\hline$\dot{S}$ & Entropy rate, W/K & $p$ & Parabolic \\
\hline$t$ & Plate thickness between flow channels, $m$ & $\mathrm{rad}$ & Due to radiation \\
\hline$T$ & Temperature, $\mathrm{K}$ & rec & Receiver tube \\
\hline$T^{*}$ & Apparent exergy-source sun temperature, $\mathrm{K}$ & reg & Recuperator channel \\
\hline$U$ & Radiation heat loss coefficient & $s$ & Surface \\
\hline$V$ & Velocity, $\mathrm{m} / \mathrm{s}$ & sph & Spherical receiver \\
\hline$w$ & Wind speed, $\mathrm{m} / \mathrm{s}$ & $t$ & Turbine \\
\hline & & $w$ & Receiver inner wall \\
\hline
\end{tabular}

